\title{
LÀM KHỚP DỊ THƯỜNG TRỌNG LỰC VỆ TINH VỚI KẾT QUẢ ĐO TRỌNG LỰC TRỰC TIẾP
}

\author{
NGUYẼ̃N VĂN SÁNG(1), ĐINH XUÂN MẠNH ${ }^{(2)}$ \\ ${ }^{(1)}$ Truò̀ng Đại học Mỏ - Địa chất \\ (2) Viện Khoa học Đo đạc và Bản đồ
}

\section{Tóm tắt:}

Dị thường trọng lự vệ tinh luôn có độ lệch so với kết quả đo trong lục trục tiếp. Truớc khi sủ dụng, cần phải làm khớp chúng với nhau. Phuơng pháp Collocation cho phép làm khớp hai loại dị thương trọng lực này. Truớc khi làm khớp cần hiệu chỉnh độ lệch hệ thống. Tính toán thực nghiệm đã thưc hiện làm khớp dị thuoòng trọng lự vệ tinh DTU15GRAV với 3017 kết quả đo trọng lực trục

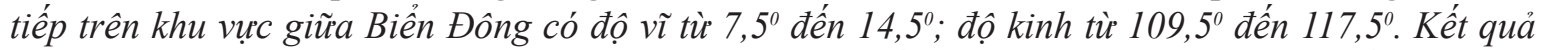
làm khớp được so sánh với 1065 điểm đo trong lục trục tiếp để đánh giá độ chính xác. Kết quả đánh giá cho thấy, sau khi làm khớp, độ chính xác của dị thuờng trọng lực vệ tinh được tăng tù̀ $\pm 7,23$ mGal lên $\pm 5,07$ m Gal.

\section{Giới thiệu}

Một trong những ứng dụng hiệu quả của đo cao vệ tinh là xác định dị thường trọng lực biển. Đã có nhiều các kết quả nghiên cứu xác định dị thường trọng lực biển từ số liệu đo cao vệ tinh (sau đây gọi là dị thường trọng lực vệ tinh) như: Mô hình DNSC08GRA có độ phân giải (1'x1') được Đan Mạch xây dựng năm 2008 từ số liệu của các vệ tinh Geosat, ERS-1, ERS2, T/P, Jason-1, Envisat, GFO và ICEsat [1]. Mô hình DTU10GRAV được nâng cấp từ mô hình DNSC08GRAV trên cơ sở bổ sung thêm các số liệu đo mới của vệ tinh ERS-1, ENVISAT, được công bố năm 2010 [3]. Mô hình DTU13GRAV được xây dựng năm 2013 [4]. Năm 2015, Andersen, Ole Baltazar và Per đã xây dựng mô hình DTU15GRAV có độ phân giải (1'x1'), trên cơ sở sử dụng 5 năm dữ liệu của vệ tinh Cryosat - 2 và dữ liệu của vệ tinh Jason-2 [2].

Trên Biển Đông, đã có một số các công trình nghiên cứu xác định dị thường trọng lực từ số liệu đo cao vệ tinh như: Năm 2011, Neiman Y. M và Nguyễn Văn Sáng đã xác định dị thường trọng lực từ số liệu 2 chu kỳ vệ tinh ENVISAT [6]. Trong [7], tác giả đã xác định được dị thường trọng lực trên Biển Đông từ số liệu 10 chu kỳ vệ tinh ENVISAT với độ chính xác đạt khoảng $\pm 6 \mathrm{mGal}$. Trong tài liệu [11], năm 2018, các tác giả đã xác định dị thường trọng lực bằng số liệu đo cao vệ tinh Cryosat-2 trên vùng biển Vịnh Bắc Bộ - Việt Nam. Trong [10], năm 2019, các tác giả đã xác định dị thường trọng lực bằng số liệu đo cao vệ tinh Cryosat-2 trên vùng biển xung quanh Quần đảo Trường Sa. Năm 2020, trong [9], các tác giả đã xác định dị thường trọng lực bằng số liệu đo cao vệ tinh Cryosat-2 và Saral/Altika trên vùng biển Vịnh Bắc Bộ - Việt Nam. Trong [8], các tác giả đã đánh giá độ chính xác của các mô hình DTU10GRAV, DTU13GRAV, và DTU15GRAV bằng cách so sánh với dị thường trọng lực đo trực tiếp trên tàu.

Một trong những đặc điểm chung của các kết quả nghiên cứu này là dị thường trọng lực vệ tinh thường bị lệch so với dị thường trọng lực đo trực tiếp trên tàu. Do đó, trước khi sử dụng các kết quả nghiên cứu này, cần làm khớp dị thường trọng lực vệ tịn với dị thường trọng lực đo trực tiếp. Bài báo này sẽ đưa ra phương pháp làm khớp chúng và tiến hành thực nghiệm trên khu vực giữa Biển Đông.

Ngày nhận bài: 15/5/2021, ngày chuyển phản biện: 19/5/2021, ngày chấp nhận phản biện: 25/5/2021, ngày chấp nhận đăng: 29/5/2021 


\section{Số liệu và khu vực nghiên cứu}

\subsection{Khu vẹc nghiên cúu}

Khu vực nghiên cứu là khu vực giữa Biển Đông có độ vĩ $\mathrm{B}$ từ $7,5^{\circ}$ đến $14,5^{\circ}$; độ kinh $\mathrm{L}$ từ $109,5^{\circ}$ đến $117,5^{\circ}$ (Hình 1).

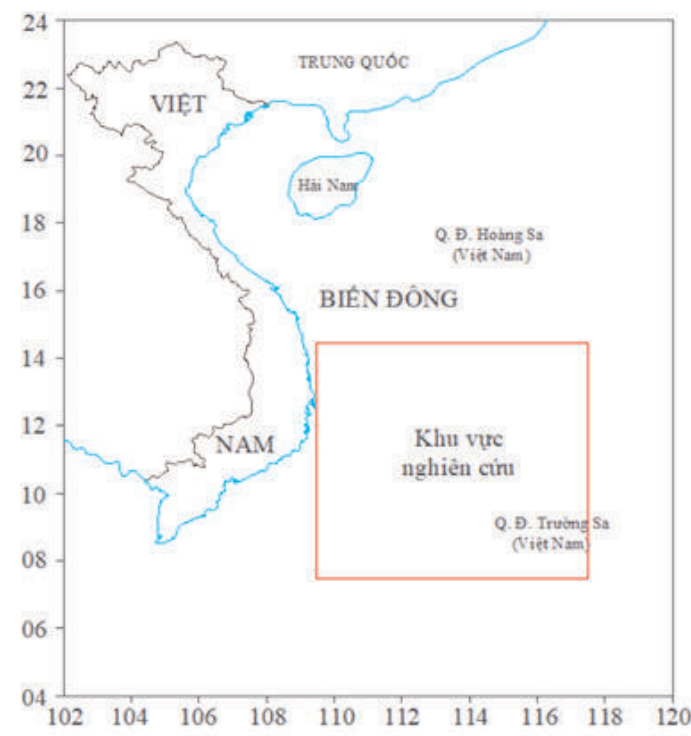

Hìn 1: Khu vục nghiên cứu

\subsection{Số liệu nghiên cứu}

\subsubsection{Số liệu dị thường trọng lục vệ tinh}

Dị thường trọng lực vệ tinh trên khu vực nghiên cứu được lấy từ mô hình DTU15GRAV. Mô hình này được các nhà khoa học của Trung tâm Vũ trụ quốc gia Đan Mạch (Danish National Space Center - DNSC) thuộc Trường Đại học tổng hợp Kỹ thuật Đan Mạch (Technical University of Denmark DTU) xây dựng năm 2015, trên cơ sở nâng cấp DTU13GRAV. Mô hình này được cải thiện rất nhiều do có nhiều số liệu ở nhiệm vụ trắc địa của vệ tinh Jason-1 và số liệu vệ tinh Cryosat-2. Những vệ tinh mới này cung cấp số trị đo nhiều gấp ba lần so với trước đây. Dữ liệu mới này cải thiện đáng kể chất lượng của mô hình, đặc biệt là bước sóng ngắn hơn của trường trọng lực $(10-20 \mathrm{~km})$ [2]. Số liệu dị thường trọng lực vệ tinh ở dạng grid với kích thước mắt lưới 1'x1'. Trên khu vực nghiên cứu có tổng cộng 203404 điểm. Các điểm này có tọa độ trong hệ WGS-84.

\subsubsection{Số liệu trọng lực đo trục tiếp}

Số liệu trọng lực đo trực tiếp được thực hiện những năm 1987, 1990 và 1992 trong các dự án hợp tác giữa Việt Nam với Nga và Việt Nam với Pháp. Các số liệu này có độ tin cậy cao, các thông số rất rõ ràng, đạt độ chính xác cao [5]. Các số liệu này nằm trong hệ tọa độ quốc tế WGS-84. Trên khu vực nghiên cứu có 4235 điểm đo trọng lực trực tiếp, được thể hiện trên Hình 2. Các điểm đo tập trung ở phía Tây của khu vực nghiên cứu. Phía Đông là vùng trũng sâu của Biển Đông nên không có số liệu. Số liệu đo này được chia làm 2 phần: phần 1 gồm 3170 điểm (các điểm màu xanh) sẽ dùng để làm khớp với dị thường trọng lực vệ tinh; phần 2 gồm 1065 điểm (các điểm màu đỏ) sẽ dùng để kiểm tra, đánh giá độ chính xác dị thường trọng lực vệ tinh trước và sau làm khớp. 


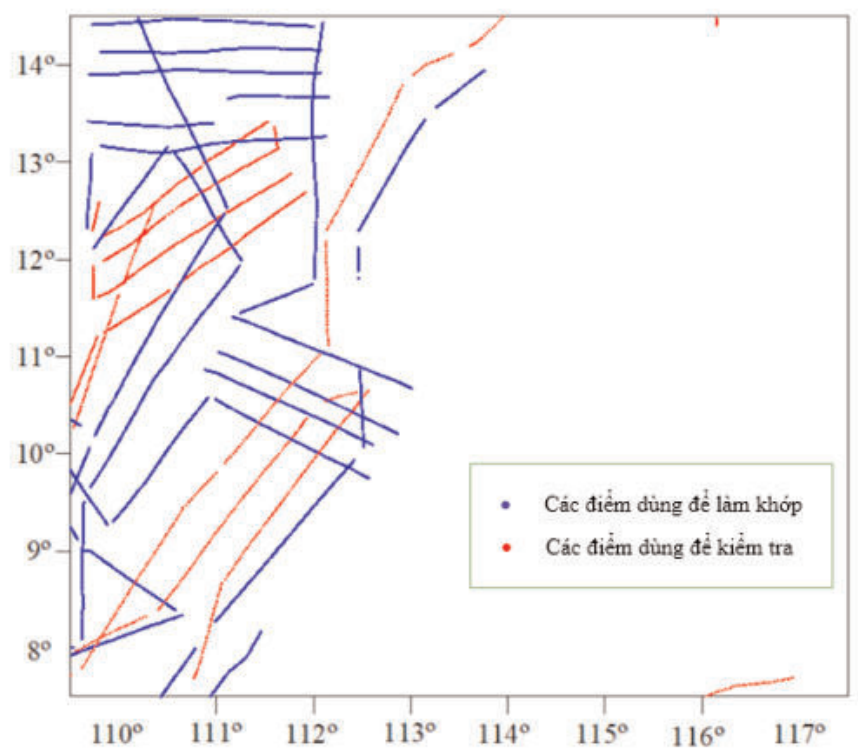

Hình 2: Phân bố các điểm đo trọng lục trụcc tiếp

\section{Phương pháp làm khớp dị thường trọng lực vệ tinh với kết quả đo trọng lực trực tiếp}

\section{1. Đánh giá độ chính xác dị thuờng trọng lục vệ tinh trước khi làm khớp}

Dị thường trọng lực vệ tinh trước khi làm khớp được so sánh với dị thường trọng lực đo trực tiếp tại 1065 điểm (các điểm màu đỏ trên hình 2) để đánh giá độ chính xác. Độ lệch dị thường trọng lực được tính theo công thức:

$$
\delta g_{i}=\Delta g_{i}^{\text {do }}-\Delta g_{i}^{\text {alt }}, i=1,2, \ldots, n ; n=1065 .
$$

trong đó: $\Delta g_{i}^{\text {åo }}$ là dị thường trọng lực tính từ kết quả đo trọng lực trực tiếp; $\Delta g_{i}^{\text {alt }}$ là dị thường trọng lực vệ tinh.

Độ lệch trung bình: $\delta g_{T B}=\frac{1}{n} \sum_{i=1}^{n} \delta g_{i}$.

Độ lệch chuẩn:

Độ lệch trung phương: $R M S=\sqrt{\frac{1}{n} \sum_{i=1}^{n} \delta g_{i}^{2}}$

$$
\sigma_{g}=\sqrt{\frac{1}{n-1} \sum_{i=1}^{n}\left(\delta g_{i}-\delta g_{T B}\right)^{2}} .
$$

Kết quả đánh giá độ chính xác như sau: Độ lệch lớn nhất =9,43 mGal; Độ lệch nhỏ nhất = -24,43 $\mathrm{mGal}$; Độ lệch trung bình = -5,04 mGal; Độ lệch chuẩn = =5,20 mGal; Độ lệch trung phương = $\pm 7,23 \mathrm{mGal}$.

Như vậy, so sánh với kết quả đo trọng lực trực tiếp, dị thường trọng lực vệ tinh trên khu vực nghiên cứu có chứa sai lệch hệ thống, thể hiện ở độ lệch trung bình là $-5,04 \mathrm{mGal}$ và đạt độ chính xác là $\pm 7,23 \mathrm{mGal}$.

\subsection{Làm khớp dị thường trọng lục vệ tinh với kết quả đo trọng lục trục tiếp bằng phương pháp}

\section{Collocation}

- Hiệu chỉnh sai số hệ thống: Như trên đã thấy, dị thường trọng lực vệ tinh có chứa sai lệch hệ thống so với dị thường trọng lực đo trực tiếp. Do đó, trước khi làm khớp chúng bằng phương pháp 
Collocation thì cần phải hiệu chỉnh sai lệch hệ thống này. Lượng hiệu chỉnh chính bằng độ lệch trung bình tính từ 4235 điểm.

- Làm khớp bằng phương pháp Collocation: Sau khi đã hiệu chỉnh độ lệch hệ thống, việc làm khớp được thực hiện bằng phương pháp Collocation như sau:

Giả sử trên khu vực nghiên cứu có $k$ giá trị dị thường trọng lực xác định từ số liệu đo cao vệ tinh $\Delta g_{1}^{a l t}, \Delta g_{2}^{a l t}, \ldots, \Delta g_{k}^{a l t} \quad$ và $m$ giá trị dị thường trọng lực tính từ số liệu đo trọng lực trực tiếp $\Delta g_{1}^{\Delta 0}, \Delta g_{2}^{\Delta \circ}, \ldots, \Delta g_{m}^{\Delta 0}$

Khi đó, theo phương pháp Collocation, dị thường trọng lực của điểm $P$ được tính bằng công thức [7]:

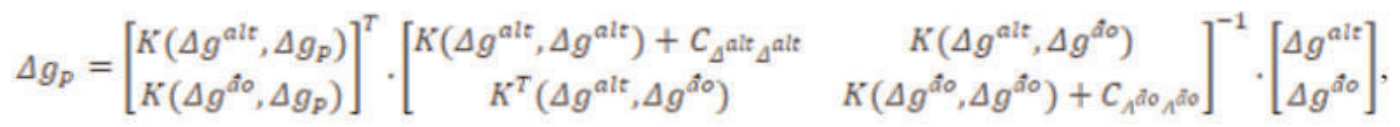

trong đó: $K(\Delta g, \Delta g)$ - ma trận hiệp phương sai của dị thường trọng lực;

$C_{\Delta \Delta}$ - ma trận hiệp phương sai của sai số đo;

$$
\begin{aligned}
& K^{T}\left(\Delta g^{\text {alt }}, \Delta g_{P}\right)=\left[K\left(\Delta g_{1}^{\text {alt }}, \Delta g_{P}\right) \quad K\left(\Delta g_{2}^{\text {alt }}, \Delta g_{P}\right) \quad \ldots \quad K\left(\Delta g_{k}^{\text {alt }}, \Delta g_{P}\right)\right] ;
\end{aligned}
$$

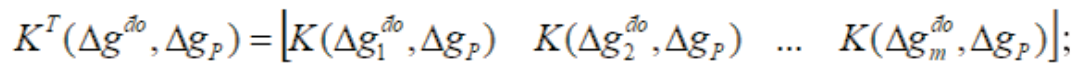

$$
\begin{aligned}
& K\left(\Delta g^{\text {alt }}, \Delta g^{\text {alt }}\right)=\left[\begin{array}{cccc}
K\left(\Delta g_{1}^{\text {alt }}, \Delta g_{1}^{\text {alt }}\right) & K\left(\Delta g_{1}^{\text {alt }}, \Delta g_{2}^{\text {alt }}\right) & \ldots & K\left(\Delta g_{1}^{\text {alt }}, \Delta g_{k}^{\text {alt }}\right) \\
K\left(\Delta g_{2}^{\text {alt }}, \Delta g_{1}^{\text {alt }}\right) & K\left(\Delta g_{2}^{\text {alt }}, \Delta g_{2}^{\text {alt }}\right) & \ldots & K\left(\Delta g_{2}^{\text {alt }}, \Delta g_{k}^{\text {alt }}\right) \\
\ldots & \ldots & \ldots & \ldots \\
K\left(\Delta g_{k}^{\text {alt }}, \Delta g_{1}^{\text {alt }}\right) & K\left(\Delta g_{k}^{\text {alt }}, \Delta g_{2}^{\text {alt }}\right) & \ldots & K\left(\Delta g_{k}^{\text {alt }}, \Delta g_{k}^{\text {alt }}\right)
\end{array}\right]
\end{aligned}
$$

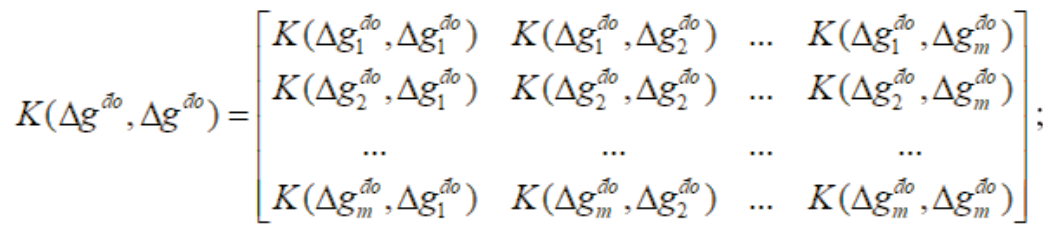

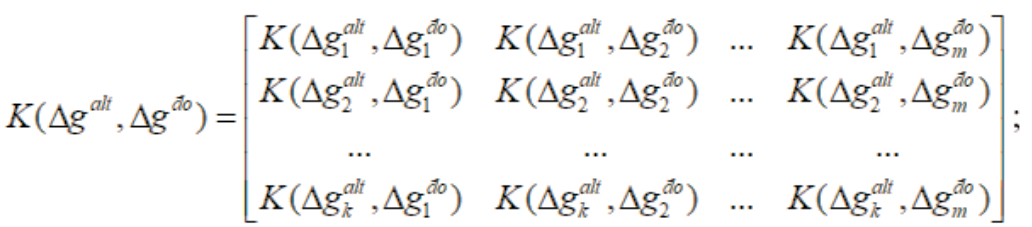

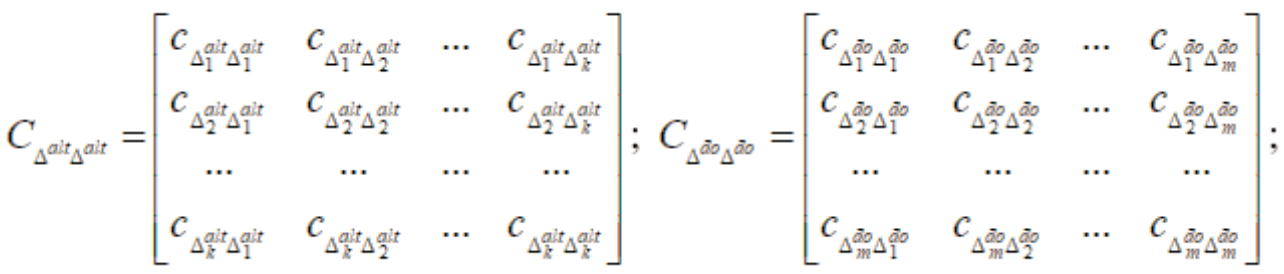


Các tham số của hàm hiệp phương sai sẽ được xác định bằng cách làm khớp hàm hiệp phương sai lý thuyết với các giá trị hiệp phương sai thực nghiệm. Tính các giá trị hiệp phương sai thực nghiệm theo số liệu dị thường trọng lực đã biết [7].

\section{Kết quả thực nghiệm làm khớp dị thường trọng lực vệ tinh với kết quả đo trọng lực trực tiếp trên khu vực nghiên cứu}

\subsection{Kết quả xác định hiệp phương sai thục nghiệm và lý thuyết}

Từ số liệu thực nghiệm, các giá trị hiệp phương sai thực nghiệm đã được tính toán. Các giá trị này được sử dụng để xác định các tham số của hàm hiệp phương sai lý thuyết. Các kết quả tính toán được trình bày trên bảng 1 .

Bảng 1: Kết quả tính hiệp phuơng sai

\begin{tabular}{|c|c|c|c|c|c|c|c|c|c|c|c|}
\hline \multirow{2}{*}{ STT } & \multirow{2}{*}{$\begin{array}{c}\text { Khoảng } \\
\text { cách } \\
(\mathrm{Km})\end{array}$} & \multicolumn{2}{|c|}{$\begin{array}{l}\text { Hiệp phương sai } \\
\text { (mGal2) }\end{array}$} & \multirow{2}{*}{ STT } & \multirow{2}{*}{$\begin{array}{c}\text { Khoảng } \\
\text { cách } \\
(\mathrm{Km})\end{array}$} & \multicolumn{2}{|c|}{$\begin{array}{l}\text { Hiệp phương sai } \\
\text { (mGal2) }\end{array}$} & \multirow{2}{*}{ STT } & \multirow{2}{*}{$\begin{array}{c}\text { Khoảng } \\
\text { cách } \\
(\mathrm{Km})\end{array}$} & \multicolumn{2}{|c|}{$\begin{array}{l}\text { Hiệp phương sai } \\
\text { (mGal2) }\end{array}$} \\
\hline & & $\begin{array}{c}\text { Thực } \\
\text { nghiệm }\end{array}$ & $\begin{array}{l}\text { Lý } \\
\text { thuyết }\end{array}$ & & & $\begin{array}{c}\text { Thực } \\
\text { nghiệm }\end{array}$ & $\begin{array}{c}\text { Lý } \\
\text { thuyêt }\end{array}$ & & & $\begin{array}{c}\text { Thực } \\
\text { nghiệm }\end{array}$ & $\begin{array}{c}\text { Lý } \\
\text { thuyết }\end{array}$ \\
\hline 1 & 0 & 564.32 & 564.32 & 18 & 34 & 239.32 & 250.28 & 35 & 68 & 149.51 & 145.53 \\
\hline 2 & 2 & 557.20 & 547.62 & 19 & 36 & 239.83 & 241.53 & 36 & 70 & 147.00 & 141.33 \\
\hline 3 & 4 & 542.86 & 514.35 & 20 & 38 & 229.91 & 233.25 & 37 & 72 & 142.00 & 137.27 \\
\hline 4 & 6 & 518.65 & 480.76 & 21 & 40 & 228.58 & 225.39 & 38 & 74 & 138.72 & 133.35 \\
\hline 5 & 8 & 488.20 & 450.72 & 22 & 42 & 219.30 & 217.92 & 39 & 76 & 135.77 & 129.57 \\
\hline 6 & 10 & 449.32 & 424.37 & 23 & 44 & 218.35 & 210.81 & 40 & 78 & 131.34 & 125.90 \\
\hline 7 & 12 & 425.18 & 401.16 & 24 & 46 & 209.99 & 204.02 & 41 & 80 & 131.17 & 122.36 \\
\hline 8 & 14 & 387.43 & 380.54 & 25 & 48 & 207.35 & 197.54 & 42 & 82 & 125.72 & 118.93 \\
\hline 9 & 16 & 356.80 & 362.04 & 26 & 50 & 202.86 & 191.34 & 43 & 84 & 126.50 & 115.60 \\
\hline 10 & 18 & 333.38 & 345.29 & 27 & 52 & 194.99 & 185.40 & 44 & 86 & 122.08 & 112.39 \\
\hline 11 & 20 & 314.42 & 330.03 & 28 & 54 & 190.77 & 179.70 & 45 & 88 & 121.47 & 109.27 \\
\hline 12 & 22 & 294.33 & 316.01 & 29 & 56 & 182.01 & 174.24 & 46 & 90 & 117.72 & 106.24 \\
\hline 13 & 24 & 283.14 & 303.07 & 30 & 58 & 181.12 & 168.99 & 47 & 92 & 115.66 & 103.31 \\
\hline 14 & 26 & 272.30 & 291.06 & 31 & 60 & 169.75 & 163.94 & 48 & 94 & 112.34 & 100.47 \\
\hline 15 & 28 & 260.78 & 279.86 & 32 & 62 & 169.09 & 159.08 & 49 & 96 & 110.40 & 97.71 \\
\hline 16 & 30 & 253.44 & 269.39 & 33 & 64 & 159.19 & 154.39 & 50 & 98 & 105.99 & 95.04 \\
\hline 17 & 32 & 248.74 & 259.55 & 34 & 66 & 156.42 & 149.88 & 51 & 100 & 103.75 & 92.44 \\
\hline
\end{tabular}

Đồ thị của hàm hiệp phương sai lý thuyết và các giá trị hiệp phương sai thực nghiệm được trình bày trên hình 3 .

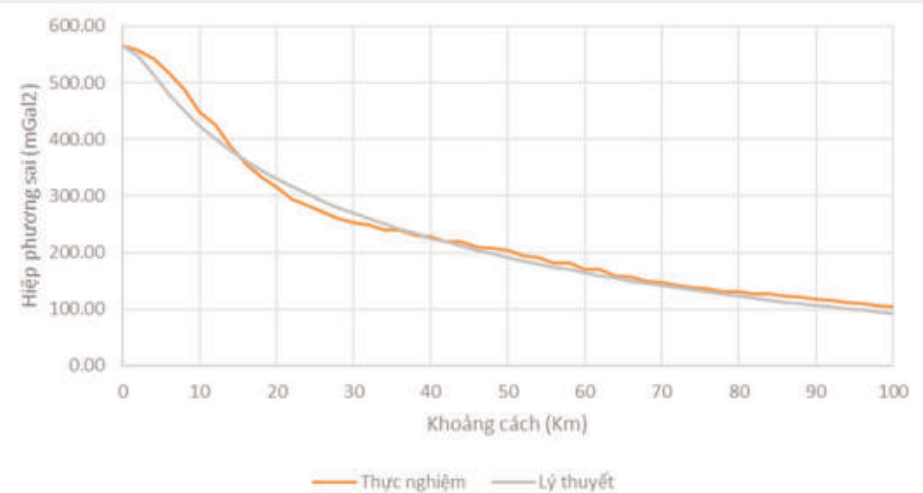

Hình 3: Đồ thị của hàm hiệp phuoong sai lý thuyết và các giá trị hiệp phuơng sai thực nghiệm 


\subsection{Dị thưòng trong lục sau khi làm khớp}

Sau khi làm khớp, dị thường trọng lực được trình bày ở dạng đường đẳng dị và màu sắc như trên hình 4.

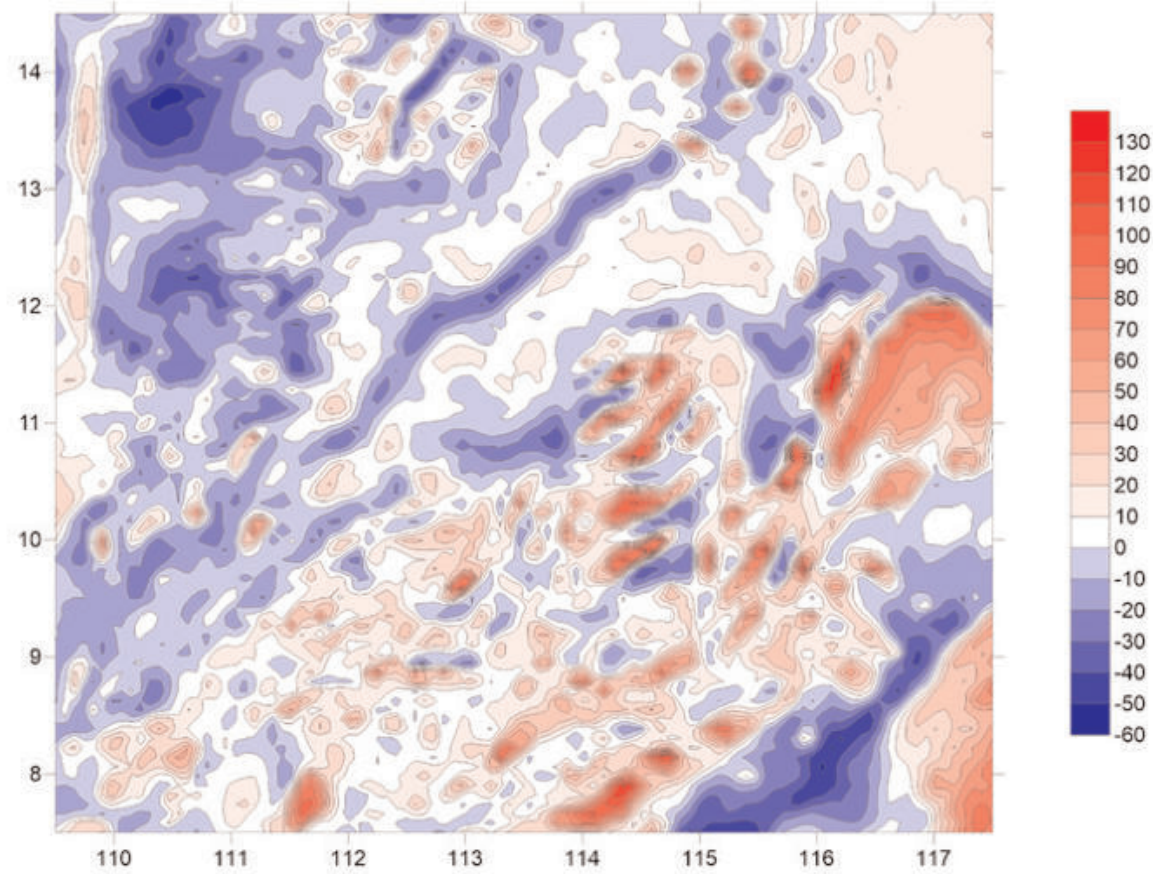

Hình 4: Dị thường trọng lục sau khi làm khớp

\subsection{Kết quả đánh giá độ chính xác sau khi làm khớp}

Sau khi làm khớp, dị thường trọng lực vệ tinh được so sánh với kết quả đo trọng lực trực tiếp tại 1065 điểm đo (các điểm màu đỏ trên hình 1) để đánh giá độ chính xác. Kết quả đánh giá độ chính xác trình bày trong bảng 2 .

Bảng 2: Độ chính xác của dị thường trọng lục vệ tinh truớc và sau khi làm khớp

\begin{tabular}{|l|c|c|c|c|c|c|}
\hline $\begin{array}{c}\text { Phương án so sánh, } \\
\text { dánh giá }\end{array}$ & Số điềm & $\begin{array}{c}\text { Max } \\
(\mathrm{mGal})\end{array}$ & $\begin{array}{c}\text { Min } \\
(\mathrm{mGal})\end{array}$ & $\begin{array}{c}\text { Mean } \\
(\mathrm{mGal})\end{array}$ & $\begin{array}{c}\text { Stand.D } \\
(\mathrm{mGal})\end{array}$ & $\begin{array}{c}\text { RMSD } \\
(\mathrm{mGal})\end{array}$ \\
\hline Trước làm khớp & 1065 & 9,43 & $-24,43$ & $-5,04$ & 5,20 & 7,23 \\
\hline Sau làm khớp & 1065 & 14,45 & $-19,43$ & $-0,06$ & 5,07 & 5,07 \\
\hline
\end{tabular}

Từ kết quả trên bảng 2 cho thấy: sau khi làm khớp, độ lệch trung bình xấp xỉ bằng 0 , chứng tỏ độ lệch hệ thống đã được loại bỏ trên toàn bộ số liệu. Độ chính xác của dị thường trọng lực vệ tinh tăng lên thể hiện ở độ lệch trung phương giảm từ $\pm 7,23 \mathrm{mGal}$ xuống $\pm 5,07 \mathrm{mGal}$. Tuy nhiên, cần lưu ý rằng: theo [7] thì các điểm đo sâu trọng lực bằng tàu có ảnh hưởng trong phạm vi $0,4^{0}$ xung quanh điểm đo.

Biểu đồ tần suất độ lệch được trình bày trong hình 5 cho thấy: độ lệch tuân theo quy luật của sai số ngẫu nhiên. (Xem hình 5) 


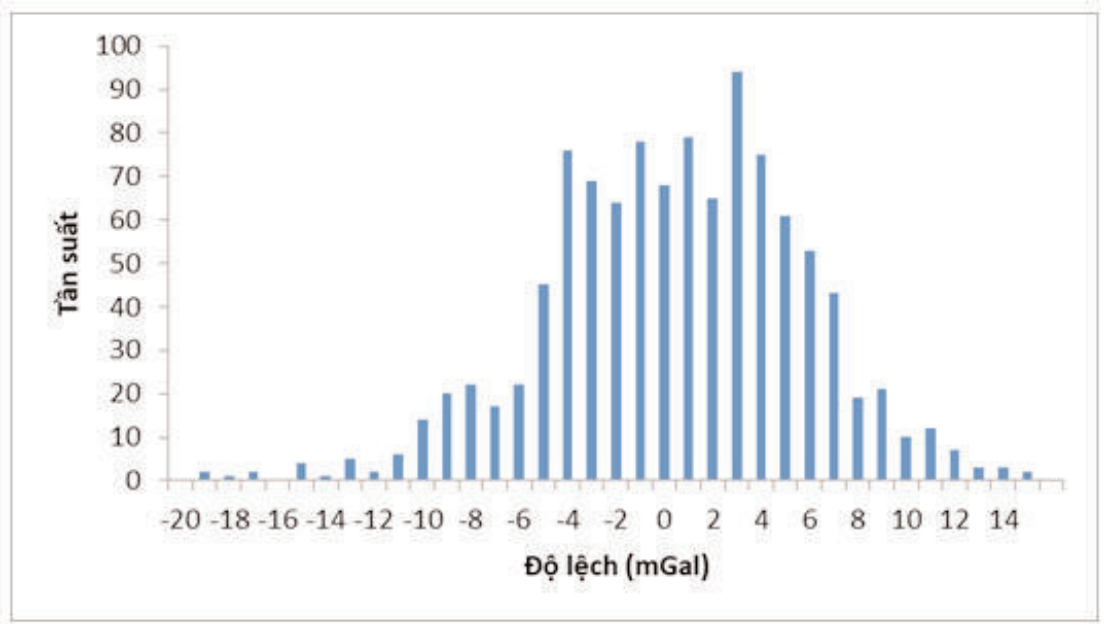

Hìn 5: Biểu đồ tần suất độ lệch

\section{Kết luận}

Dị thường trọng lực vệ tinh luôn có độ lệch so với kết quả đo trọng lực trực tiếp. Trước khi sử dụng, cần phải làm khớp hai loại dị thường trọng lực này. Phương pháp Collocation cho phép làm khớp chúng. Trước khi làm khớp cần hiệu chỉnh độ lệch hệ thống.

Trên khu vực thực nghiệm, độ chính xác của dị thường trọng lực vệ tinh lấy từ mô hình DTU15GRAV sau khi làm khớp với kết quả đo trọng lực trực tiếp đã tăng từ $\pm 7,23$ mGal lên $\pm 5,07$ mGal. Độ lệch có tính chất ngẫu nhiên và tuân theo luật phân bố chuẩn. $\bigcirc$

\section{Lò̀i cảm ơn}

Các kết quả nghiên cứu của bài báo này là sản phẩm của đề tài cấp bộ "Nghiên cứu đề xuất phương pháp xác định độ sâu đáy biển từ số liệu dị thường trọng lực trên khu vực Biển Đông" mã số: B2021-MDA-06. Các tác giả xin gửi lời cảm ơn đến Bộ Giáo dục và Đào tạo, Trường Đại học Mỏ - Địa chất đã hỗ trợ chúng tôi trong các nghiên cứu này.

\section{Tài liệu tham khảo}

[1]. Andersen O. B. et al., 2010. The DNSC08GRA global marine gravity field from double retracked satellite altimetry, Journal of Geodesy.

[2]. Andersen O. B. et al., 2016. Deriving the DTU15 Global high resolution marine gravity field from satellite altimetry, ESA Living Planet Symposium 2016.

[3]. Andersen O., 2010. The DTU10 gravity field and mean sea surface, Second international symposium of the gravity field of the Earth (IGFS2), Fairbanks, Alaska.

[4]. Andersen, O.B., Knudsen, P., Kenyon, S., et al., 2014. Global and arctic marine gravity field fromrecent satellite altimetry (DTU13). 76th EAGE Conference and Exhibition http://dx.doi.org/10.3997/2214-4609.20140897.

[5]. Bui Cong Que, Tran Tuan Dung, Le Tram, 2008. Construction of bouguer gravity anomaly 
map in the East Vietnam Sea and adjacent area. Vietnam Journal of Marine Science and Technology. Vietnam Academy of Science and Technology.

[6]. Neiman Y. M., Nguyễn Văn Sáng, 2011. Xác định dị thường trọng lực trên biển Việt Nam bằng số liệu đo cao vệ tinh ENVISAT, Tạp chí trắc địa và chụp ảnh hàng không (số $5, \operatorname{tr} 15$ - 21), Matxcova (tiếng Nga). ISSN: 0536 - 101X.

[7]. Nguyễn Văn Sáng, 2012. Xác định dị thường trọng lực cho vùng biển Việt Nam bằng kết quả đo cao vệ tinh. Luận án tiến sỹ khoa học kỹ thuật. Trường đại học tổng hợp Trắc địa và Bản đồ Matxcova, Liên Bang Nga (tiếng Nga).

[8]. Nguyễn Văn Sáng, 2020. Đánh giá độ chính xác của mô hình dị thường trọng lực toàn cầu xác định từ đo cao vệ tinh trên Biển Đông. Tạp chí Công nghiệp mỏ (số 01, 2/2020, tr 65-68). Hội khoa học và Công nghệ mỏ Việt Nam, Hà Nội. ISSN: 0868 - 7052.

[9]. Nguyen Van Sang, Pham Van Tuyen, Nguyen Van Lam, Ole Baltazar Andersen, Rene Forsberg, Bui Tien Dieu, 2020. Marine Gravity Anomaly Mapping for the Gulf of Tonkin area (Vietnam) using Cryosat-2 and Saral/AltiKa satellite altimetry data. Advances in Space Research. ISSN: 0273-1177. DOI: https://doi.org/10.1016/j.asr.2020.04.051.

[10]. Nguyen Van Sang, Vu Van Tri, Pham Van Tuyen, 2019. Determination of Marine Gravity Anomalies in the Truong Sa Archipelago's Sea Territory Using Satellite Altimeter Data. FIG Working Week 2019. Geospatial information for a smarter life and environmental resilience, Hanoi, Vietnam, April 22-26, 2019.

[11]. Phạm Văn Tuyên, Nguyễn Văn Sáng, 2018. Kết quả xác định dị thường trọng lực bằng số liệu đo cao vệ tinh Cryosat-2 trên vùng biển Vịnh Bắc Bộ - Việt Nam. Tạp chí khoa học kỹ thuật Mỏ - Địa Chất (tập 59, kỳ 2, tr 60 - 68), trường Đại học Mỏ - Địa Chất, Hà Nội. ISSN: 1859 - 1469.O

\section{Summary}

\section{Fitting satellite-derived gravity anomalies with ship-measured gravity anomalies}

Nguyen Van Sang

Hanoi University of Mining and Geology

\section{Dinh Xuan Manh}

\section{Vietnam Institute of Geodesy and Cartography}

The satellite-derived gravity anomalies always deviate from the ship-measured gravity anomalies. Before use, it is necessary to fit them together. Collocation method allows fitting of these two types of gravity anomalies. Before fitting, it is necessary to correct the system deviation. Experimental calculations made the DTU15GRAV satellite-derived anomalies fit with 3017 shipmeasured gravity anomalies points in the middle East Sea with latitude from $7.5^{\circ}$ to $14.5^{\circ}$; longitude from $109.5^{\circ}$ to $117.5^{\circ}$. Fitting results were compared with 1065 ship-measured gravity anomalies points to evaluate accuracy. Evaluation results show that, after the fitting, the accuracy of satellitederived gravity anomalies increased from $\pm 7.23 \mathrm{mGal}$ to $\pm 5.07 \mathrm{mGal} . \bigcirc$ 